NEUROGASTROENTEROLOGY

\title{
Increased antigen and bacterial uptake in follicle associated epithelium induced by chronic psychological stress in rats
}

\author{
Å K Velin, A-C Ericson, Y Braaf, C Wallon, J D Söderholm
}

Gut 2004;53:494-500. doi: 10.1136/gut.2003.028506

See end of article for authors' affiliations

.....................

Correspondence to: Dr J D Söderholm, Department of Biomedicine and Surgery, Division of Surgery, University

Hospital, 58185

Linköping, Sweden;

johda@ibk.liu.se

Accepted for publication

28 October 2003
Background: Chronic stress affects the course of inflammatory bowel disease and experimental colitis, and may also initiate intestinal inflammation in rats.

Aim: To investigate the effects of stress on the $M$ cell containing follicle associated epithelium, specialised in antigen uptake.

Subjects and methods: Wistar rats were submitted to acute water avoidance stress for one hour or chronic water avoidance stress for 1 hour/day for 10 consecutive days. Permeability to ${ }^{51} \mathrm{Cr}$-EDTA, horseradish peroxidase, and chemically killed Escherichia coli K-12 was studied in both villus and follicle associated epithelium in Ussing chambers. Segments were further examined by light, electron, and confocal microscopy.

Results: Acute stress increased horseradish peroxidase flux in villus as well as in follicle associated epithelium. Chronic stress further increased permeability to horseradish peroxidase in villus and follicle associated epithelium, in the latter by almost fourfold. Moreover, chronic stress induced over 30 times increased $E$ coli passage in follicle associated epithelium whereas there was no significant increase in villus epithelium. Bacterial uptake was confirmed by confocal microscopy showing fluorescent bacteria penetrating and passing through the epithelial surface.

Conclusions: These results show that the barrier function of follicle associated epithelium can be modulated, and that chronic stress enhances the uptake of luminal antigens and bacteria via the follicle associated epithelium. This can increase antigen exposure in Peyer's patches thereby having implications in the initiation of proinflammatory immune responses within the intestinal mucosa.
$\mathrm{T}$ he follicle associated epithelium (FAE) that covers Peyer's patches is an important route for the uptake of antigens and bacteria into the intestinal mucosa. ${ }^{12}$ The FAE contains membranous $(M)$ cells and thereby it has unique biochemical properties, facilitating adherence, uptake, and immunological sampling of microorganisms. ${ }^{2}$ Adherent materials are endocytosed by $M$ cells and transported to the underlying lymphoid tissue. It is well accepted that inflammatory bowel disease (IBD) is associated with an antigenic load from luminal dietary products and bacteria. ${ }^{3}$ As FAE is an entry site for bacteria, and IBD is associated with an increased immune reaction to non-specific bacteria, ${ }^{45}$ dysfunction in the regulation of FAE could be involved in IBD. The possibility of dysregulated FAE in IBD is strengthened by the fact that the earliest observable signs of Crohn's disease (CD) are aphthoid ulcers originating from the FAE. ${ }^{6} 7$

It is believed that chronic stress modulates inflammatory activity in IBD. ${ }^{8}$ Severe stress episodes are an important risk factor for the development and reactivation of intestinal inflammation in rodents ${ }^{10}$ and in humans. ${ }^{11}{ }^{12}$ Moreover, environmental stress can alter the course of CD. ${ }^{13}$ In animal models, stress induced mucosal dysfunction mainly involves corticotropin releasing hormone, mast cells, and cholinergic neurones. ${ }^{14-16}$ In rat villus epithelium (VE), acute stress increases intestinal permeability to macromolecules without causing changes in gut morphology. ${ }^{17-19}$ However, when exposing rats to repetitive stress, the outcome is a further increase in permeability, bacterial attachment, mast cell hyperplasia, and initiation of inflammation..$^{21}$

Although FAE is an important route of entry for bacteria and antigens, to date no reports have studied stress effects on barrier function in the FAE. Therefore, the present study was designed to investigate the functional and morphological effects of stress in FAE. Rats were submitted to acute or chronic stress, and intestinal segments of FAE and VE were mounted in Ussing chambers for permeability measurements and studies of bacterial uptake. Segments were further processed for examination by light, electron, and confocal microscopy.

\section{MATERIALS AND METHODS \\ Animals}

The study was approved by the local committee of animal ethics. Thirty six male Wistar rats (B\&K Universal $A B$, Sollentuna, Sweden), body weight 150-200 g at arrival, were used. After arrival, rats were acclimatised for one week and then handled daily for two weeks before the stress protocols were initiated. During these three weeks, and the rest of the experimental period, animals were kept under pathogen free conditions with a 12:12 hour light:dark cycle and fed ad libitum on a diet of standard rat pellets (R70; Lactamin AB, Vadstena, Sweden) and tap water.

\section{Acute stress}

Six rats were subjected to acute stress, with one hour of water avoidance stress (WAS), and six other rats were subjected to sham stress (SS) and used as controls. WAS rats were placed on a platform (height $8 \mathrm{~cm}$, depth $6 \mathrm{~cm}$ ) in a plastic container (height $56 \mathrm{~cm}$, depth $50 \mathrm{~cm}$ ) with $25^{\circ} \mathrm{C}$ water, $1 \mathrm{~cm}$ below the platform. SS rats were treated in exactly the

Abbreviations: $C D$, Crohn's disease; $F A E$, follicle associated epithelium; HRP, horseradish peroxidase, IBD, inflammatory bowel disease; M cell, membranous cell; SS, sham stress; VE, villus epithelium; WAS, water avoidance stress; PBS, phosphate buffered saline 
same way as WAS rats except that during the stress session SS rats were placed on a similar platform but in a waterless container. After one hour, the number of faecal pellets were counted as an indirect index of changes in colonic propulsive activity. ${ }^{22}$ Rats were anaesthetised by isoflurane inhalation and $15 \mathrm{~cm}$ segments from the distal ileum (starting $5 \mathrm{~cm}$ proximal to the ileocaecal valve) were taken out and immediately transported to the laboratory in ice cold oxygenated Krebs buffer (115 mM NaCl, $1.25 \mathrm{mM} \mathrm{CaCl}_{2}$, $1.2 \mathrm{mM} \mathrm{MgCl}_{2}, 2 \mathrm{mM} \mathrm{KH}_{2} \mathrm{PO}_{4}$, and $25 \mathrm{mM} \mathrm{NaHCO}$, $\mathrm{pH} 7.35)$.

\section{Chronic stress}

The results of the acute stress experiments confirmed stress mediated effects on FAE. As chronic stress is more interesting from a pathogenic point of view, 24 Wistar rats were subjected to WAS or SS (controls) for 10 consecutive days, $1 \mathrm{~h}$ /day. To minimise the effect of circadian rhythm, the procedures were started between 9am and 10am. Before each session, rats were weighed, while the number of faecal pellets were counted following the WAS or SS period. After the final period, rats were anaesthetised and intestinal segments were taken out as described above. Blood for corticosterone analysis was collected by cardiac puncture and centrifuged at $3000 \mathrm{~g}$ for 10 minutes. The collected serum was stored at $-70^{\circ} \mathrm{C}$ until further use for corticosterone assay (see below).

\section{Ussing chamber experiments}

While immersed in ice cold oxygenated Krebs, the external muscle and myenteric plexus were stripped of distal ileal specimens. Sections of VE and FAE, identified macroscopically, were cut into appropriate sizes and mounted in modified Ussing chambers (Harvard apparatus Inc., Holliston, Massachusetts, USA). ${ }^{23}$ When mounting FAE, segments were carefully adjusted so that the patches covered the entire exposed tissue surface area of $0.096 \mathrm{~cm}^{2}$. Before placing the chambers in the $37^{\circ} \mathrm{C}$ system, the mucosal compartments were filled with $1.5 \mathrm{ml}$ of cold $10 \mathrm{mM}$ mannitol in Krebs buffer and the serosal compartments were filled with $10 \mathrm{mM}$ glucose in Krebs buffer. Both sides were continuously oxygenated, $95 \% \mathrm{O}_{2} / 5 \% \mathrm{CO}_{2}$, and circulated by gas flow. Each chamber had two pairs of $\mathrm{Ag} / \mathrm{AgCl}$ electrodes with agar-salt bridges to monitor the transepithelial potential difference, short circuit current, and electrical resistance across the tissue. Tissue conductance, representing passive paracellular passage to ions, was calculated. To achieve steady state conditions in the transepithelial potential difference, chambers were equilibrated for 40 minutes with replacement of $37^{\circ} \mathrm{C}$ mannitol or glucose buffer at 20 minutes.

\section{Macromolecular passage}

For acute stress, 12 VE and 12 FAE segments from six rats per group were mounted in Ussing chambers. For chronic stress, $18 \mathrm{VE}$ and 18 FAE segments from 12 rats per group were mounted. The $45 \mathrm{kDa}$ protein antigen horseradish peroxidase (HRP) (type VI; Sigma Chemical Co., St Louis, Missouri, USA) was used for transcellular studies. For paracellular studies, the 384 Da inert probe ${ }^{51} \mathrm{Cr}$-EDTA (Perkin Elmer, Boston, Massachusetts, USA) was used. After equilibration, $300 \mu \mathrm{l}$ of serosal samples were collected and replaced with glucose buffer. HRP and ${ }^{51} \mathrm{Cr}$-EDTA were added to the mucosal side to a final concentration of $10^{-5} \mathrm{M}$ and $34 \mu \mathrm{Ci} / \mathrm{ml}$, respectively. Serosal samples were then collected at 30, 60, and 90 minutes after the start. An aliquot from each sample was saved for HRP analysis (see below) and the remainder was placed in a gamma counter (1282 Compugamma; LKB, Bromma, Sweden) for ${ }^{51}$ Cr-EDTA measurements. To determine the passage routes for HRP, 17 FAE segments from six chronic WAS rats and 14 from six SS rats were mounted in chambers, and HRP was added at a final concentration of $10^{-5} \mathrm{M}$ to the mucosal side. After 15,30 , and 60 minutes, segments were fixed in situ in the chambers with $2 \%$ glutaraldehyde. After two hours, segments were carefully removed to vials containing $0.1 \mathrm{M}$ sodium cacodylate buffer $(\mathrm{pH} 7.4)$ and stored at $4^{\circ} \mathrm{C}$ until processed for electron microscopy (see below).

\section{Bacterial passage}

For chronic stress, $18 \mathrm{VE}$ and 18 FAE segments from six rats per group were mounted in Ussing chambers. After equilibration, chemically killed fluorescein conjugated Escherichia coli K-12 BioParticles (Molecular Probes, Leiden, the Netherlands) were added to the mucosal side of the reservoirs at a final concentration of $1 \times 10^{8} \mathrm{CFU} / \mathrm{ml}$. Bacteria are killed with paraformaldehyde which stops their reproduction but retains antigenicity. After 45, 90, and 120 minutes, the entire volume of the serosal compartments were collected and analysed at $488 \mathrm{~nm}$ in a fluorimeter (Cary Eclipse, Varian, Victoria, Australia). Segments were fixed in situ in the chambers with $4 \%$ formaldehyde in phosphate buffered saline (PBS) for three hours and stored in the dark at $4^{\circ} \mathrm{C}$ until further use for confocal microscopy (see below).

\section{Corticosterone assay}

Total corticosterone in blood samples from chronic stressed rats was analysed by the IDS OCTEIA corticosterone kit (IDS, Boldon, U.K) according to the manufacturer's instructions. All samples were run in duplicate and kit calibrators and controls were included in each analysis. Absorbances were measured at $450 \mathrm{~nm}$, with a reference wavelength of $650 \mathrm{~nm}$, in an ELISA microtitre plate reader (Anthos htIII; Anthos, Labtec Instruments, Salzburg, Germany). A calibration curve was prepared on semi-log graph paper and values for each unknown sample were read off the curve in $\mathrm{ng} / \mathrm{ml}$.

\section{HRP assay}

HRP was measured using the QuantaBlu Fluorgenic Peroxidase Substrate Kit (Pierce, Rockford, USA). Samples collected from the serosal side of the chambers were diluted in Krebs buffer with $0.02 \%$ bovine serum albumin and $50 \mu \mathrm{l}$ was transferred to dark microtitre plates. To each well, $100 \mu \mathrm{l}$ of QuantaBlu working solution (QuantaBlu Stable peroxidase solution diluted 1:10 in QuantaBlu substrate solution) was added and the plate was incubated in a shaker at $300 \mathrm{rpm}$ at room temperature. After exactly 30 minutes, $100 \mu \mathrm{l}$ of QuantaBlu stop solution was added and 10 minutes later absorbance of the coloured reaction product was measured at an excitation wavelength of $325 \mathrm{~nm}$ and emission wavelength of $420 \mathrm{~nm}$ using a fluorimeter (Cary Eclipse, Varian, Victoria, Australia). Blanks were included in each analysis and all samples were run in duplicate and measured against a standard curve. Intravariability coefficient was estimated as $8.6 \%$ and intervariability coefficient $9.3 \%$.

\section{Microscopic examination}

\section{Electron microscopy}

Glutaraldehyde fixed segments were washed in Tris buffer and incubated with $0.6 \mathrm{mg} / \mathrm{ml} \mathrm{DAB}-3 \% \mathrm{H}_{2} \mathrm{O}_{2}$ for 30 minutes. Tissues were transferred to $0.1 \mathrm{M}$ cacodylate buffer, $\mathrm{pH} 7.4$, with $1 \%$ osmium $(1: 1)$, and after one hour washed in cacodylate buffer, dehydrated, and embedded in Epon (TAAB 812; Analytical Standards, Gothenburg, Sweden). Sections were stained with lead citrate and examined by transmission electron microscopy (JEM-1230; JEOL Sollentuna, Sweden). 


\section{Confocal microscopy}

Tissues were rinsed in PBS and labelled with $5 \mu \mathrm{g} / \mathrm{ml}$ wheat germ agglutinin conjugated to Alexa Flour 594 (Molecular Probes) to visualise the epithelial cell surface. After repeated washing in PBS, tissues were mounted in glycerol and examined in a Nikon Eclipse E600W confocal laser scanning microscope (Nikon, NY, USA) with a $60 \times$ oil immersion objective. An ion laser permitted simultaneous excitation wavelengths of $488 \mathrm{~nm}$ for fluorescein labelled $E$ coli and $594 \mathrm{~nm}$ for Alexa labelled wheat germ agglutinin.

\section{Light microscopy}

Segments of VE from three randomly selected rats per group were frozen in liquid nitrogen, embedded in mounting medium, and cryosectioned at $3 \mu \mathrm{m}$. Coded slides were fixed in acetone for 10 minutes and stained with May-Grünvald/ Giemsa. Cells identified as mast cells were counted in three tissues per rat using Easy Image software (Tekno Optik AB, Stockholm, Sweden) connected to a Nikon Eclipse 800 light microscope with an $60 \times$ oil immersion objective. For each tissue, eight non-overlapping areas $\left(37 \mu \mathrm{m}^{2}\right)$ above the muscularis mucosa were examined.

\section{Statistics}

Parametric values are presented as mean (SEM). Comparisons between two groups were performed using the Student's $t$ test, and between more than two groups using one way ANOVA. Non-parametric values are given as median (25-75th interquartile range). Comparisons between two groups were done using the Mann-Whitney $U$ test and between more than two groups with the Kruskal-Wallis one way ANOVA. Differences with $\mathrm{p}<0.05$ were considered significant.

\section{RESULTS}

FAE is responsive to acute stress

Acute stress significantly increased the frequency of defecation (12.3 (2.3) $v$ controls 1.8 (0.8) pellets/h; $\mathrm{p}<0.0005)$. Moreover, acute stress exposure significantly increased the short circuit current and electrical conductance in both VE and FAE (fig lA). There were no changes in ${ }^{51} \mathrm{Cr}$-EDTA permeability after stress exposure in VE $(4.3(0.7) v$ controls $\left.4.5(0.9) 10^{-6} \mathrm{~cm} / \mathrm{s}\right)$ or FAE (8.0 (1.6) $\left.v 7.0(0.8) \mathrm{cm} / \mathrm{s}\right)$. However, HRP flux was increased in both VE (15.1 (3.4) $v$ controls 11.1 (6.6) pmol/h/ $/ \mathrm{cm}^{2}$ ) and FAE (36.9 (10.7) $v 21.8$ (6.7) $\mathrm{pmol} / \mathrm{h} / \mathrm{cm}^{2}$ ). FAE was significantly more permeable than VE to both probes.

\section{Changes in systemic parameters and electrophysiology by chronic stress}

During the experimental period, stressed rats stagnated in weight (mean weight was $293 \mathrm{~g}$ on day $\mathrm{l}$ and $298 \mathrm{~g}$ on day 10) whereas control rats continued to gain weight (mean weight was $287 \mathrm{~g}$ on day $\mathrm{l}$ and $324 \mathrm{~g}$ on day 10). The difference in weight gain between controls and stressed rats was significant from day 4 of the stress period $(p<0.05)$. Chronic stress significantly increased the defecation rate at each stress session, and the rate was consistently increased for each daily session over the 10 day period. The mean number of faecal pellets expelled daily over the period was 9.9 (0.3) pellets/h (range 7-15) in stressed rats and $2.4(0.2)$ (range $0-4)$ in controls $(p<0.0005)$. Serum corticosterone levels were elevated after 10 days of stress $(215.4(20.0) \mathrm{v}$ controls 123.0 (9.8) ng/ml; $\mathrm{p}<0.0005)$. Furthermore, chronic stress exposure almost tripled the number of ileal mucosal mast cells $\left(68(3.0) v\right.$ controls $23(1.7)$ cells $\left./ \mathrm{mm}^{2} ; \mathrm{p}<0.0005\right)$, and electron microscopy showed signs of mast cell degranulation in stressed rats. Rats exposed to chronic stress showed
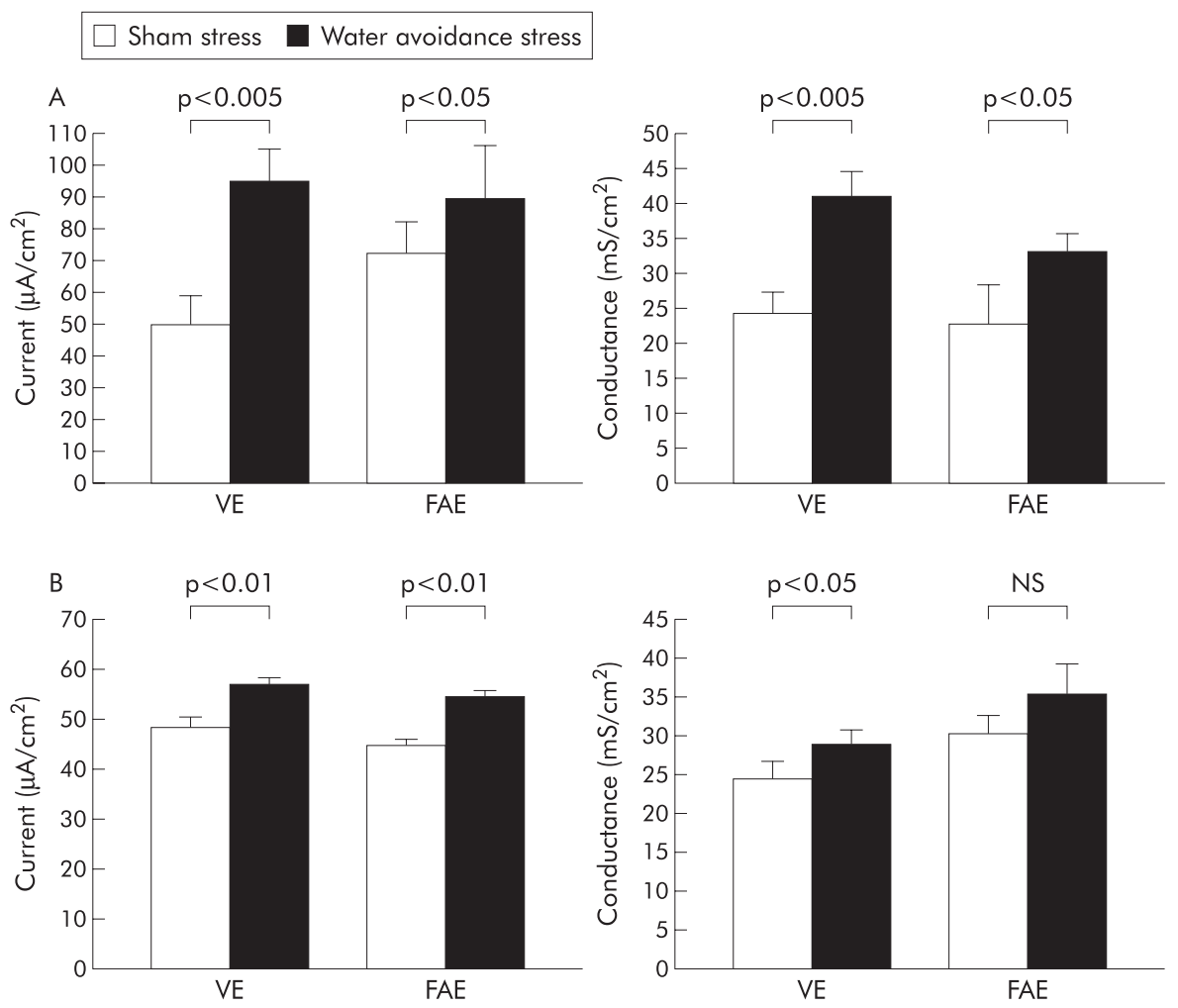

Figure 1 Effects of acute (A) and chronic (B) stress on short circuit current (left) and electrical conductance (right). Rats were subjected to sham stress or water avoidance stress. lleal segments from villus epithelium (VE) and follicle associated epithelium (FAE) were mounted in Ussing chambers. (A) Effects of acute stress (one hour), 6 rats/group. (B) Effects of chronic stress (one hour for 10 consecutive days), 12 rats/group. Bars represent mean (SEM). Comparisons were done using ANOVA. 

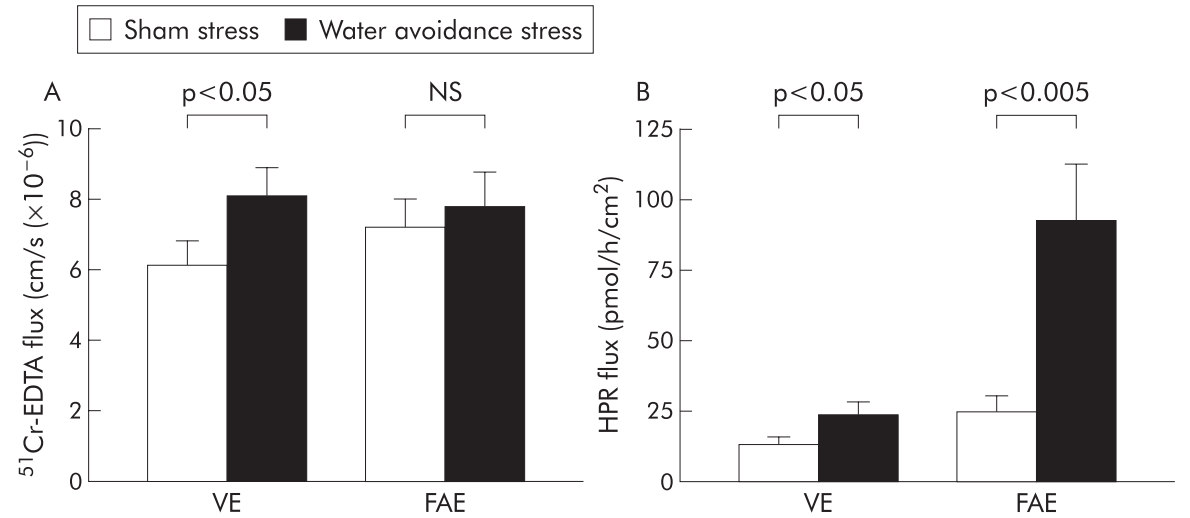

Figure 2 Effects of chronic stress on permeability. Rats were subjected to sham stress or water avoidance stress for 10 consecutive days, 12 rats/ group. lleal segments from villus epithelium (VE) and follicle associated epithelium (FAE) were mounted in Ussing chambers. (A) ${ }^{51} \mathrm{Cr}$-EDTA-flux in VE and FAE. (B) Horseradish peroxidase flux (HPR) in VE and FAE. Bars represent mean (SEM). Comparisons were done using ANOVA.

a significant increase in short circuit current in both VE and FAE whereas electrical conductance was significantly increased in VE but not in FAE (fig 1B).

\section{Pronounced chronic stress induced increase in FAE uptake of HRP}

Permeability to ${ }^{51} \mathrm{Cr}$-EDTA was increased in VE after stress exposure (8.1 (0.8) $v$ controls $\left.6.1(0.7) 10^{-6} \mathrm{~cm} / \mathrm{s} ; \mathrm{p}<0.05\right)$ whereas there was no significant change in FAE $(7.8(1.0) v$ 7.2 (0.8); $\mathrm{p}=0.08$ ) (fig 2A). Chronic stress enhanced HRP flux in VE $\left(24.3(4.3) \quad v\right.$ controls $13.6 \quad(2.5) \mathrm{pmol} / \mathrm{h} / \mathrm{cm}^{2}$; $\mathrm{p}<0.05)$ and caused a pronounced increase in HRP flux in FAE (92.5 (20.2) v 25.5 (4.8); p<0.005) (fig 2B).

\section{Ultrastructural changes in FAE by chronic stress}

FAE from control rats demonstrated a normal morphology whereas stressed animals in some areas revealed abnormal epithelial cell morphology with vacuoles (fig 3A, B). Uptake of HRP was observed in all segments investigated, and occasionally bacteria penetrating into enterocytes were seen. Within the FAE, M cells with uptake of HRP in direct contact with lymphocytes were identified between enterocytes (fig 4A, B). M cells were identified according to definitions for identification previously established ${ }^{124}$ : irregularly shaped apical surface, short microvilli, attenuated cytoplasm, invaginated basolateral membrane with pockets containing lymphocytes and macrophages, and prominent vesicles.

\section{Chronic stress induced bacterial internalisation via the FAE}

Examination by electron microscopy illustrated signs of bacterial penetration into the enterocytes of the FAE of stressed rats. To further explore the effects of stress on bacterial passage, uptake was quantified by Ussing chamber experiments (table 1). After 45 minutes, there were no significant differences in $E$ coli passage between FAE from stressed rats and controls. After 90 minutes, passage was slightly elevated in stressed rats and after 120 minutes it was increased more than 30-fold. Bacterial uptake was confirmed by confocal microscopy where it was shown that after 45 minutes fluorescent bacteria were observed close to the epithelial surface, after 90 minutes bacteria were found penetrating the epithelium, and after 120 minutes bacteria had passed through the entire epithelial cell layer (fig 5A, B, C). In VE, E coli flux was only slightly elevated after 120 minutes in stress exposed rats (table 1).

\section{DISCUSSION}

To our knowledge, this is the first report of a stress induced increase in transcellular permeability of FAE. There was a greater than threefold increase in permeability to the antigenic protein HRP in FAE after chronic stress. Moreover, macromolecular uptake was more than three times higher in FAE than in VE of the same stressed animal.
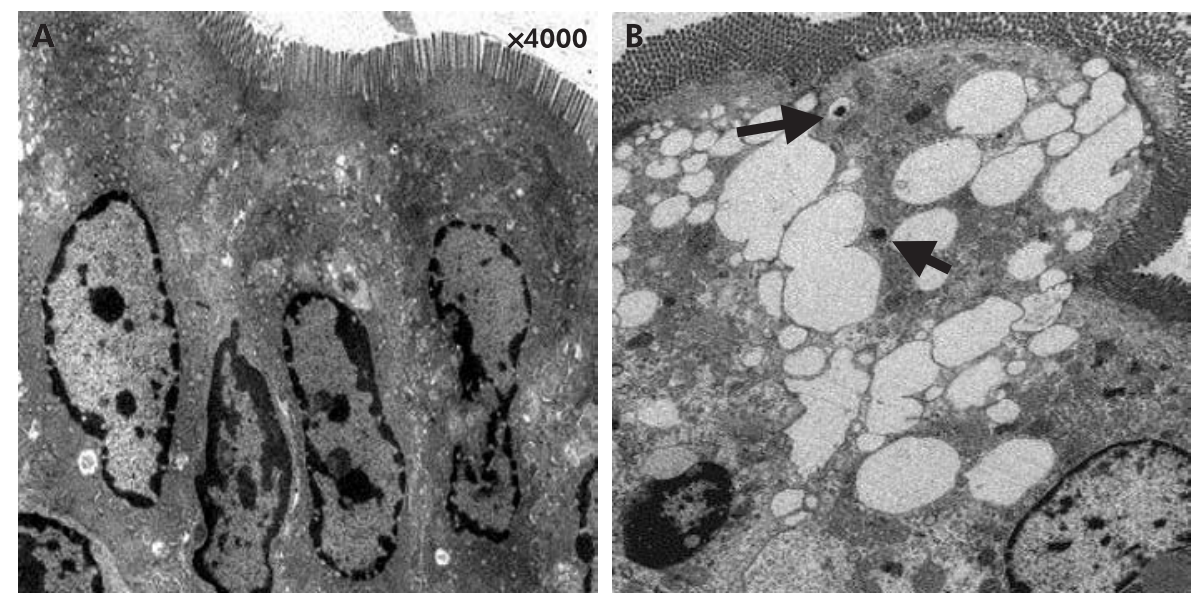

Figure 3 Effects of chronic stress on epithelial ultrastructure. (A) Follicle associated epithelium (FAE) from control rats demonstrated a normal morphology. (B) FAE from stressed rats revealed an abnormal morphology with numerous vacuoles. Arrows indicate endosomal uptake of horseradish peroxidase into epithelial cells. 

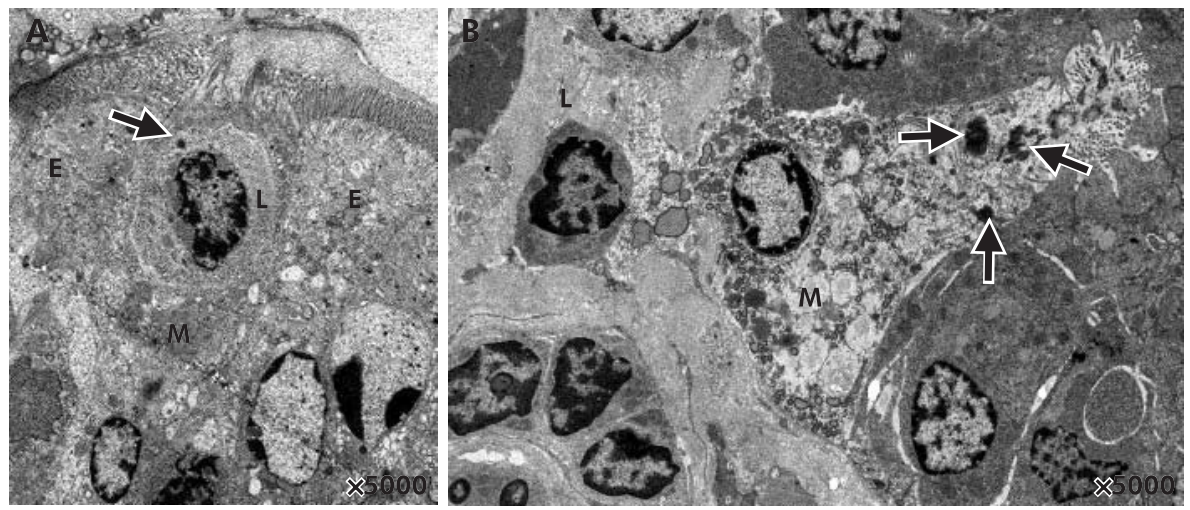

Figure 4 Membranous (M) cells identified in the follicle associated epithelium (FAE) of stressed rats. M cells were identified according to ultrastructural characteristics: irregularly shaped apical surface, short microvilli, attenuated cytoplasm, intraepithelial pockets containing lymphocytes and macrophages, and prominent vesicles.' ${ }^{24}$ (A) An M cell between two enterocytes (E). The $M$ cell has an intraepithelial pocket containing a lymphocyte (L). The arrow denotes uptake of horseradish peroxidase (HRP) into the lymphocyte. (B) Endosomal HRP uptake (arrows) into an M cell in direct contact with a lymphocyte (L).

Enhanced uptake in FAE was further emphasised by increased passage of chemically killed $E$ coli in rats exposed to chronic stress.

Under normal conditions, the HRP molecule passes through epithelial cells via pinocytosis, ${ }^{125}$ although after chronic restraint stress and in sensitised animals HRP can also permeate between cells. ${ }^{18}{ }^{26}$ In the present study, paracellular permeability to ions (conductance) was similarly affected in VE and FAE after stress. After chronic stress, permeability to the paracellular marker molecule ${ }^{51} \mathrm{Cr}$-EDTA was increased in VE but almost unaffected in FAE. In contrast, stress induced changes in permeability to proteins was significantly more pronounced in FAE, with an almost fourfold increase in HRP flux. Electron microscopy revealed that HRP was transported in endosomes via the transcellular pathway whereas no HRP staining was found in the paracellular spaces. Taken together, these findings suggest that chronic stress, in the FAE, mainly affects transcellular antigen uptake. Ultrastructural examination further revealed penetrating bacteria in FAE of stressed rats which hinted at increased uptake of bacteria. Subsequent Ussing chamber studies demonstrated that permeability to $E$ coli was more than 30 times higher in the FAE of stressed rats compared with controls, and six times higher in FAE than in VE. Although the $E$ coli strain used in our study was chemically killed, lost motility, and could not replicate, they preserved their antigenicity. These particles have been used for phagocytosis studies ${ }^{27}$ and should be a good model of bacterial invasion. With confocal microscopy, it was seen that after 45 minutes, bacteria were present on the epithelial surface, and after 120 minutes, bacteria had passed through the epithelium. Increased uptake of bacteria by the FAE reflects a region made permeable to normally non-invasive bacteria. It may be speculated that a significant part of the bacterial translocation that takes part in various stress reactions may be due to invasion via the FAE, as revealed by our studies. As the earliest signs of CD are aphthoid ulcers in the FAE, barrier dysfunction of the FAE may be involved in the early stages of this disease.

In VE, conductance was, as in previous studies, ${ }^{20} 2128$ enhanced by both acute and chronic stress. In contrast, permeability to the paracellular probe ${ }^{51} \mathrm{Cr}$-EDTA was increased only by chronic stress. This finding suggests partially different mechanisms involved in the paracellular permeability defect induced by acute and chronic stress. Recently, Ferrier et $a l^{29}$ found that in vivo permeability to ${ }^{51} \mathrm{Cr}$-EDTA in the mouse colon was unaffected by a single stress episode whereas repeated stress over 3-4 days induced a pronounced increase in paracellular permeability. This barrier defect was mediated by $\mathrm{T}$ cells and interferon $\gamma$. It could be speculated that this $\mathrm{T}$ cell activation, leading to interferon $\gamma$ production and eventually increased paracellular permeability to macromolecules, is initiated by a WAS induced increase in transcellular permeability to antigens. This increase in transcellular permeability may involve mast cells. The importance of mast cells in stress induced mucosal abnormalities have been demonstrated previously. ${ }^{14} 162021$ In the present study, we found a threefold increase in the number of mucosal mast cells and signs of mast cell activation after chronic stress. The interaction between mast cells and nerves has been widely discussed, and it is known that in response to stress, mast cells secrete mediators that affect nerves and immune cells. ${ }^{30}$ Direct contact between gastrointestinal mast cells and nerves has also been reported in the small intestine, ${ }^{31}$ but whether the altered FAE function seen in the present study involves nerve-mast cell interaction

Table 1 Effects of chronic stress on bacterial passage

\begin{tabular}{llll}
\hline Group, tissue & $\mathbf{4 5}$ min passage & $\mathbf{9 0}$ min passage & $\mathbf{1 2 0}$ min passage \\
\hline WAS, FAE & $0.6(0.3-1.2)$ & $4.3(2.0-5.9)$ & $47.9(17.6-94.7)^{*} \dagger$ \\
SS, FAE & $0.0(0.0-0.0)$ & $1.8(1.2-2.2)$ & $1.4(0.9-5.1)$ \\
WAS, VE & $0.4(0.1-0.7)$ & $2.2(1.5-7.3)$ & $7.8(6.4-19.3) \ddagger$ \\
SS, VE & $0.6(0.4-1.4)$ & $3.9(3.6-4.2)$ & $5.0(3.0-5.8)$ \\
\hline
\end{tabular}

Rats were subjected to water avoidance stress (WAS) or sham stress (SS) for 10 days, $1 \mathrm{~h} /$ day, 6 rats/group. Segments of villus epithelium (VE) and follicle associated epithelium (FAE) were mounted in Ussing chambers. Passage of chemically killed $E$ coli K-12 was studied over time.

Values are presented as median (25-75th interquartile range).

Comparisons between groups were performed using Kruskal-Wallis one way ANOVA: ${ }^{*} p<0.005$ versus SS FAE; $t p<0.05$ versus WAS VE; $\neq p<0.05$ versus SS VE. 

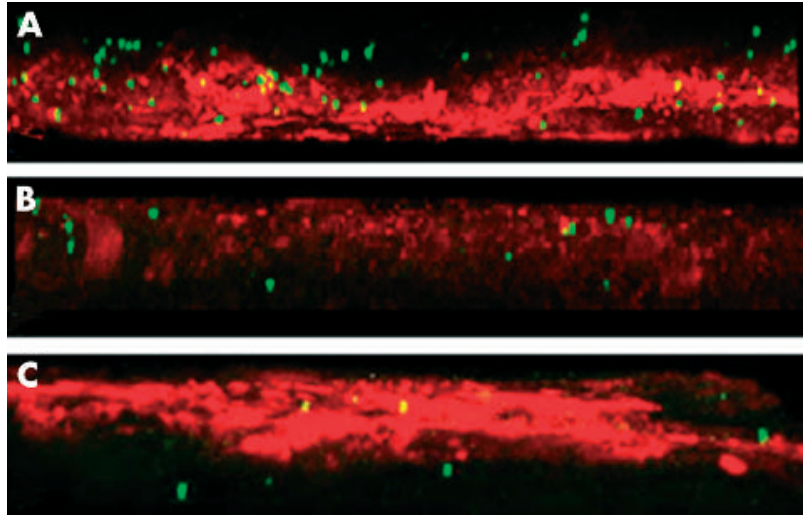

Figure 5 Bacterial passage in follicle associated epithelium (FAE) studied by confocal microscopy. Three dimensional reconstructions were made using Nikon EZ-Cl software. Rats were subjected to water avoidance stress for 10 days, $1 \mathrm{~h} /$ day, 6 rats/group. Segments of FAE were mounted in Ussing chambers and passage of chemically killed Escherichia coli K-12 was studied over time. (A) After 45 minutes, bacteria were seen close to the epithelial surface. (B) After 90 minutes, bacteria penetrated the epithelium. (C) After 120 minutes, bacteria had passed through the epithelium. Red = Alexa Flour 594 conjugated wheat germ agglutinin, green = fluorescein conjugated $E$ coli K-12.

remains to be elucidated. Nevertheless, the responsiveness of FAE to acute stress suggests neurally mediated effects on FAE permeability. However, another possibility could be corticosterone mediated effects on barrier function which has been shown in vivo in severe acute stress. ${ }^{32}$

The present study clearly demonstrates the importance of FAE in the uptake of luminal antigens. Its superior uptake capacity compared with VE is partly due to $M$ cells that constitute approximately $10 \%$ of rat FAE. ${ }^{33} \mathrm{M}$ cells lack a developed microvillus border and glycocalyx coat which facilitates access for luminal pathogens. ${ }^{23}$ Previous studies showed that $M$ cell numbers were altered in bacterial eneritis, ${ }^{34}{ }^{35}$ indomethacin induced ileitis, ${ }^{36}$ and in patients with spondylarthropy. ${ }^{37}$ These studies indicate that $\mathrm{M}$ cells may play a role in the development of intestinal inflammation. The results of the present study may suggest that stress alters the function of $\mathrm{M}$ cells in the FAE. M cells meeting the criteria for identification ${ }^{124}$ were found in the FAE by electron microscopy. The close interaction between antigen, M cells, and immune cells was visualised and most likely this interaction is of major importance in the alteration of FAE function. However, more analyses are needed to determine whether the alteration involves changes in $\mathrm{M}$ cell number or activity, a problem superseded by the lack of reliable rat $\mathrm{M}$ cell markers. Cytokeratin 8 (clone 4.1.18) has been suggested but earlier studies have shown conflicting results 3638 and we have yet to obtain a specific staining. In a recent study ${ }^{40}$ it was shown that dendritic cells could extend their processes through the epithelial tight junctions and thereby sample both pathogenic and non-pathogenic luminal microbes directly, independent of $\mathrm{M}$ cells and enterocytes. Stress induced changes in dendritic cells and other immune functions in lymph follicles are important issues that need to be addressed in the continuation of this study.

In conclusion, we found that chronic stress modulated the barrier function of the FAE, allowing uptake of normally non-invasive luminal microorganisms. Enhanced bacterial uptake may lead to increased antigen load and presentation in the dome area of Peyer's patches. Thus a local inflammatory reaction could be initiated, eventually leading to intestinal inflammation. This may have implications for stress related events in IBD.

\section{ACKNOWLEDGEMENTS}

This study was supported by the Swedish Research Council, the Åke Wiberg Foundation, the Swedish Society for Medical Research, and the Broad Medical Research Program of the Eli and Edythe L Broad Foundation.

\section{Authors' affiliations}

Å K Velin, Y Braaf, C Wallon, J D Söderholm, Department of Biomedicine and Surgery, Division of Surgery, Clinical Research Centre, Faculty of Health Sciences, University Hospital, Linköping, Sweden A-C Ericson, Department of Biomedicine and Surgery, Division of Cell Biology, Clinical Research Centre, Faculty of Health Sciences, University Hospital, Linköping, Sweden

\section{REFERENCES}

1 Owen RL. Sequential uptake of horseradish peroxidase by lymphoid follicle epithelium of Peyer's patches in the normal unobstructed mouse intestine: an ultrastructural study. Gastroenterology 1977;72:440-51.

2 Neutra MR, Mantis NJ, Frey A, et al. The composition and function of $M$ cell apical membranes: implications for microbial pathogenesis. Semin Immunol 1999; 11:171-81

3 Fiocchi C. Intestinal inflammation: a complex interplay of immune and nonimmune cell interactions. Am J Physiol 1997;273:G769-75.

4 Macpherson A, Khoo UY, Forgacs I, et al. Mucosal antibodies in inflammatory bowel disease are directed against intestinal bacteria. Gut 1996;38:365-75.

5 Duchmann R, Kaiser I, Hermann E, et al. Tolerance exists towards resident intestinal flora but is broken in active inflammatory bowel disease (IBD). Clin Exp Immunol 1995; 102:448-55.

6 Fujimura Y, Kamoi R, lida M. Pathogenesis of aphthoid ulcers in Crohn's disease: correlative findings by magnifying colonoscopy, electron microscopy, and immunohistochemistry. Gut 1996;38:724-32.

7 Morson BC. The early histological lesion of Crohn's disease. Proc R Soc Med 1972;65:71-2

8 Mayer EA. The neurobiology of stress and gastrointestinal disease. Gut 2000;47:861-9.

9 Collins SM. Stress and the gastrointestinal tract IV. Modulation of intestinal inflammation by stress: basic mechanisms and clinical relevance. Am J Physiol Gastrointest Liver Physiol 2001;280:G315-18

10 Qiu BS, Vallance BA, Blennerhassett PA, et al. The role of CD4+ lymphocytes in the susceptibility of mice to stress-induced reactivation of experimental colitis. Nat Med 1999;5:1178-82.

11 Stam R, Akkermans LM, Wiegant VM. Trauma and the gut: interactions between stressful experience and intestinal function. Gut 1997;40:704-9.

12 Levenstein S, Prantera C, Varvo V, et al. Stress and exacerbation in ulcerative colitis: a prospective study of patients enrolled in remission. Am J Gastroenterol 2000;95:1213-20.

13 Ringel Y, Drossman DA. Psychosocial aspects of Crohn's disease. Surg Clin North Am 2001;81:231-52.

14 Castagliuolo I, Lamont JT, Quu B, et al. Acute stress causes mucin release from rat colon: role of corticotropin releasing factor and mast cells. Am J Physiol 1996;271:G884-92.

15 Saunders PR, Hanssen NP, Perdue MH. Cholinergic nerves mediate stressinduced intestinal transport abnormalities in Wistar-Kyoto rats. Am J Physiol 1997;273:G486-90.

16 Castagliuolo I, Wershil BK, Karalis K, et al. Colonic mucin release in response to immobilization stress is mast cell dependent. Am J Physiol 1998;274: G1094-100.

17 Saunders PR, Kosecka U, McKay DM, et al. Acute stressors stimulate ion secretion and increase epithelial permeability in rat intestine. Am J Physiol 1994;267:G794-9

18 Kiliaan AJ, Saunders PR, Bijlsma PB, et al. Stress stimulates transepithelial macromolecular uptake in rat jejunum. Am J Physiol 1998;275:G1037-44.

19 Santos J, Saunders PR, Hanssen NP, et al. Corticotropin-releasing hormone mimics stress-induced colonic epithelial pathophysiology in the rat. Am J Physiol 1999;277:G391-9.

20 Soderholm JD, Yang PC, Ceponis P, et al. Chronic stress induces mast celldependent bacterial adherence and initiates mucosal inflammation in rat intestine. Gastroenterology 2002;123:1099-108.

21 Santos J, Yang PC, Soderholm JD, et al. Role of mast cells in chronic stress induced colonic epithelial barrier dysfunction in the rat. Gut 2001;48:630-6.

22 Barone FC, Deegan JF, Price WJ, et al. Cold-restraint stress increases rat fecal pellet output and colonic transit. Am J Physiol 1990;258:G329-37.

23 Grass GM, Sweetana SA. In vitro measurement of gastrointestinal tissue permeability using a new diffusion cell. Pharm Res 1988;5:372-6.

24 Gebert A, Rothkotter HJ, Pabst R. M cells in Peyer's patches of the intestine. Int Rev Cytol 1996;167:91-159.

25 Schurmann G, Bruwer M, Klotz A, et al. Transepithelial transport processes at the intestinal mucosa in inflammatory bowel disease. Int $J$ Colorectal Dis 1999;14:41-6.

26 Berin MC, Kiliaan AJ, Yang PC, et al. The influence of mast cells on pathways of transepithelial antigen transport in rat intestine. J Immunol 1998;161:2561-6.

27 Wan CP, Park CS, Lau BH. A rapid and simple microfluorometric phagocytosis assay. J Immunol Methods 1993;162:1-7. 
28 Santos J, Benjamin M, Yang PC, et al. Chronic stress impairs rat growth and jejunal epithelial barrier function: role of mast cells. Am J Physiol Gastrointest Liver Physiol 2000;278:G847-54.

29 Ferrier L, Mazelin L, Cenac N, et al. Stress-induced disruption of colonic epithelial barrier: role of interferon-gamma and myosin light chain kinase in mice. Gastroenterology 2003;125:795-804

30 Santos J, Perdue MH. Stress and neuroimmune regulation of gut mucosal function. Gut 2000;47(suppl 4):iv49-52.

31 Stead RH, Tomioka M, Quinonez G, et al. Intestinal mucosal mast cells in normal and nematode-infected rat intestines are in intimate contact with peptidergic nerves. Proc Natl Acad Sci U S A 1987;84:2975-9.

32 Meddings JB, Swain MG. Environmental stress-induced gastrointestinal permeability is mediated by endogenous glucocorticoids in the rat. Gastroenterology 2000;119:1019-28.

33 Gebert A. The role of $M$ cells in the protection of mucosal membranes. Histochem Cell Biol 1997; 108:455-70.

34 Borghesi C, Regoli M, Bertelli E, et al. Modifications of the follicle-associated epithelium by short-term exposure to a non-intestinal bacterium. J Pathol $1996 ; 180: 326-32$
35 Savidge TC, Smith MW, James PS, et al Salmonella-induced M-cell formation in germ-free mouse Peyer's patch tissue. Am J Pathol 1991;139:177-84

36 Kucharzik T, Lugering A, Lugering $N$, et al. Characterization of $M$ cell development during indomethacin-induced ileitis in rats. Aliment Pharmacol Ther 2000; 14:247-56.

37 Cuvelier CA, Quatacker J, Mielants H, et al. M-cells are damaged and increased in number in inflamed human ileal mucosa. Histopathology 1994:24:417-26.

38 Rautenberg K, Cichon C, Heyer G, et al. Immunocytochemical characterization of the follicle-associated epithelium of Peyer's patches: anticytokeratin 8 antibody (clone 4.1.18) as a molecular marker for rat $M$ cells. Eur J Cell Biol 1996;71:363-70.

39 Onori P, Franchitto A, Sferra R, et al. Peyer's patches epithelium in the rat: a morphological, immunohistochemical, and morphometrical study. Dig Dis Sci $2001 ; 46: 1095-104$.

40 Rescigno M, Urbano M, Valzasina B, et al. Dendritic cells express tight junction proteins and penetrate gut epithelial monolayers to sample bacteria. Nat Immunol 2001;2:361-7. 